\title{
Challenging the new pensions regulator: Part one - The statutory regime
}

Received: 21st January, 2005

\section{Nicholas Heaton}

is a partner specialising in pension litigation and has acted for clients in a range of disputes, including those involving trustees' liability and pensions-related professional negligence claims. He is a member of the Lovell's pensions litigation team as well as the Association of Pension Lawyers.

\section{Lovelo Miranda}

is a solicitor in Lovell's pension litigation team with experience of acting in pensions litigation including professional negligence cases and pensions cases involving administrative law issues. He is a member of the Association of Pensions Lawyers.

Abstract This is the first of two papers looking at the options that will be available to challenge the exercise of power by the new pensions regulator ('the regulator') created by the Pensions Act 2004 ('the Act'). This paper considers what rights are provided by the Act for those concerned to make representations in relation to, or challenge decisions of the regulator. The second paper will look at the prospect of using judicial review to challenge the decisions of the regulator, and the new pensions regulator tribunal, outside the framework of the Act.

Keywords: Pensions Act 2004; pensions regulation; pensions regulator; pensions regulator tribunal; determinations; challenges; review; appeal; moral hazard

Nicholas Heaton, Lovells, Atlantic House, 50 Holborn Viaduct, London EC1A 2FG, UK.

Tel: +44 (0)207296 5919; e-mail: Nicholas.Heaton@ lovells.com

\section{Introduction}

This is the first of two papers looking at the options that will be available to challenge the exercise of power by the new pensions regulator ('the regulator') created by the Pensions Act 2004 ('the Act'). This paper considers what rights are provided by the Act for those concerned to make representations in relation to, or challenge decisions of, the regulator.

The regulatory landscape for work-based pension schemes ${ }^{1}$ is due to change radically in April 2005 when the new regulator under the Act will replace the Occupational Pensions Regulatory Authority (Opra). The regulator will have greater powers than Opra and its chief executive, Tony Hobman, has made clear in many statements that it will take a new pro-active approach.

The potential impact of the regulator has been the source of some anxiety to a wide group of individuals and businesses who are in one way or another involved with pension schemes and who may all find themselves falling within the scope of the regulator's new wider statutory powers.

Of particular concern, and a prime example of the shift towards a pro-active approach, are the new powers related to the government's much-publicised desire to protect the 
Pensions Protection Fund (PPF) against the moral hazard. This refers to the risk that employers might act to prevent the recovery of a deficit in a final salary scheme and in effect 'dump' their liabilities on the PPF. In dealing with this risk, the new regulator will not be confined to sanctions such as fines; it will be able to impose liability on those who are connected or associated (as defined in the Act) with an employer of a particular scheme by issuing contribution notices and financial support directions. Various commercial and corporate interest groups criticised the potentially very wide impact of these powers. There was, for example, concern that they would be a deterrent to investors' involvement in corporate transactions, in particular corporate rescues, because of the risk of exposure to liabilities. To allay these fears, amendments were made to the proposed legislation in Autumn, 2004, including giving the regulator the power to issue, where appropriate, clearance statements either in advance of taking a proposed act or afterwards to confirm that the regulator would not invoke its moral hazard powers against a party, except where there was a material change in circumstances.

Despite the amendments to the provisions, there are likely to be a broad group of businesses and individuals who will be affected by the regulator's determinations and who may wish to challenge those decisions. This paper considers the ways in which challenges can be made using the statutory framework provided by the Act.

\section{The statutory framework: Outline}

The detail of the regulatory procedures to be adopted will come in regulations yet to be published, but the Act itself sets out the framework for challenges to be raised consisting of:

- A structured decision-making process that must be followed before the regulator makes a determination to use a regulatory power, which gives the opportunity to those affected to make representations.

- The right to refer a decision of the regulator to a new pensions regulator tribunal for review.

- The opportunity to apply for permission to appeal on a point of law to the Court of Appeal and thereafter to the House of Lords, if the party is dissatisfied with a decision of the tribunal.

\section{The decision-making process}

The decision-making process provides the first opportunity for a party to raise any grievances it may have with regard to the regulator's proposed use of its powers. Before setting out what that process will involve, it is necessary to identify who, within the regulator, will implement that process and consider differences between the composition of the regulator and Opra.

\section{The regulator and the panel}

The regulator itself will consist of a chief executive (Tony Hobman), a non-executive chairman (David Norgrove, appointed by the Secretary of State for Work and Pensions in December 2004) and at least five other members (including two executive members) all appointed by the Secretary of State in consultation with the chairman. Of these staff, the nonexecutive members will keep the strategic direction and performance of the regulator under review, in line 
with the Higgs recommendations of January 2003 for the board of a public company.

The regulator's decision-making functions, will differ significantly from those of Opra in that, under s. 9 of the Act, it will rely upon an independent determinations panel to make many of its determinations. The panel will be entirely separate from the regulator and the board of the PPF and will not share any of the same staff. This is in contrast to Opra's current determinations committee, the members of which may be any of the Opra board members (including the Chairman) and the Chief Executive of Opra. The role of the panel will be to deal with reserved regulatory functions (as defined in Schedule 2 of the Act). This includes the main significant and serious powers of the regulator, including the moral hazard powers (issuing contribution notices or financial support directions (but not clearance statements which will be issued by the regulator itself).

The result is that, to a large extent, there will be a clear distinction in the new regulatory regime between the investigation and monitoring of schemes (carried out by the regulator), and the decisions based on information obtained (carried out by the panel). Those functions exercised by the panel will still be carried out on behalf of the regulator, however.

\section{The two types of decision-making procedure}

It is not entirely clear from the Act how the separation between the panel and the regulator will be maintained in practice, but both bodies must determine their own procedure in accordance with the framework set down in s. 93 onwards of the Act. Those provisions show that for both the regulator and the panel there will be a standard procedure and a special procedure.

The choice of procedure appears to allow for a flexible approach: urgent action can be taken through the special procedure. As will be explained below, for the parties who are likely to be affected by a proposed determination by the regulator (or the panel, where applicable), the choice of procedure will influence:

- the stage at which there is an opportunity to make representations during the decision-making process; and

- the process for making a subsequent 'reference' to the tribunal.

\section{Standard procedure - s. 96 of the Act}

This procedure will be followed by the regulator (or the panel) when it proposes to exercise its regulatory functions and there is no immediate risk to the scheme assets or interests of members. The procedure is yet to be laid down in detail, but must provide for:

- A warning notice to be given to those persons who, as it appears to the regulator, would be directly affected by the regulatory action under consideration.

- An opportunity for representations by those persons before the regulator decides whether to take regulatory action.

- A determination notice to be given to all those directly affected by the determination.

- The determination notice to include details of the right of referral to the tribunal.

If the recipient of a determination notice is aggrieved by the decision taken, it can refer the determination to the tribunal. There is a time limit to do this: a period 
of 28 days beginning with the day on which it was given (ss. 96(3) and 103(1(a)) or such other period specified (s. 103(1)(c)). The tribunal has discretion to allow a reference after the end or this period (s. 103(2)).

In many cases, the reference of a determination to the tribunal will result in postponing the time when the determination takes effect. Except in the case of specified urgent powers (s. 96(6)), the regulator (or panel) cannot exercise the determined regulatory function during the period within which the determination may be referred to the tribunal. If the determination is so referred, then the exercise of the determination is postponed until the reference, and any appeal against the tribunal's determination has been finally disposed of (s. 96(5)). In most cases, there will in effect be a stay of any determination, pending its review or appeal.

\section{Special procedure - ss. 97 to 99 of the Act}

The special procedure will apply when it is considered by the regulator (or the panel) that it must exercise a regulatory function without delay because there is an immediate risk to the interests of members of a scheme, or to the assets of such scheme. Accordingly, in such cases, there will normally be no warning notice, even to those directly affected, and there will be no opportunity for representations before the determination notice is given.

Once the determination notice has been given under the special procedure, however, the regulator must as soon as reasonably practicable thereafter review the decision (s. 99) through the panel (s. 99(10)). Although the position is not yet entirely clear, it appears that at this review stage, the parties affected would be able to make representations or raise matters for the panel to consider in its review. The panel may then confirm, vary, revoke or substitute the determination made, by way of a final notice.

Only the final notice may be referred to the tribunal for review. The time limits for such a referal are the same as under the standard procedure. If the final notice contains a determination to exercise a different regulatory function to the original determination notice then that new function cannot be exercised during the period within which the determination may be referred to the tribunal and, if it is referred, until the disposal of that reference and any subsequent appeal - except in certain urgent circumstances — ss. 99(8) to (10).

\section{The tribunal}

\section{Who can bring a reference?}

There are two categories of party (applicant) who can refer a determination of the regulator (or panel) to the tribunal:

- Automatic right: Any person to whom the determination notice was given under the standard procedure or any person to whom a final notice was given under the special procedure (ss. 96(3)(a), 99(7)(a)) has an automatic right to make a reference. These would be the persons that the regulator considered would be 'directly affected' by the determination.

- Permission: Those not served with a determination notice or final notice may also apply to the tribunal for permission to make a reference to it on the grounds that they are, in fact, also 'directly affected' by the determination in question (ss. 96(3)(b), 99(7)(b)). 
Exclusion of determinations to issue clearance statements

It should be noted that determinations of the regulator to issue a clearance statement under ss. 42 or 46 of the Act are expressly excluded from being the subject of a reference to the tribunal (s. 96(4)). This makes some sense, given the context in which clearance statements are likely to be sought, for example in relation to transactions. The Act provides that once given, a clearance statement binds the regulator in relation to the issue of contribution notices or financial support directions (subject to any material change of circumstance). The intention is clearly that the applicant should be able to rely on the clearance statement once issued, without fear of it being overturned by the tribunal or having to wait until the period for review has passed. It does, however, mean that there is no effective remedy within the statutory framework for parties who wish to challenge the decision to give a clearance statement, for example, trustees or members of a pension scheme who are concerned about the impact of a transaction on their scheme. Whether such parties could use avenues outside the statutory framework to challenge such decisions, such as judicial review, will be considered in the second paper. It does appear that where the regulator has refused to issue a clearance statement, that determination can be referred to the tribunal for review.

\section{Differences between the tribunal and the previous regime}

Decisions of Opra are currently reviewed by its review committee. This is an internal Opra body whose members may be any of the board members (including the Chairman and the Chief Executive but not anyone who sat on the
Determination Committee, which made the determination under review). By contrast, under the new regime, the tribunal will be an independent body supervised and appointed by the Lord Chancellor (s. 102 of the Act). It will draw upon a panel of chairmen, who will be experienced lawyers, and a lay panel (of people qualified by experience or otherwise to deal with matters of the kind that may be referred to the tribunal).

A further difference between the tribunal and the current Opra review committee will be the tribunal's greater flexibility in dealing with references to it. The review committee can only review Opra's determinations if it is satisfied that there has been a relevant change of circumstances since the determination was made, or that the determination was made in ignorance of a material fact or based on a mistake as to a material fact or was erroneous in point of law (s. 96(3) Pensions Act 1995). The tribunal's function is more open: it must 'determine what (if any) is the appropriate action for the regulator to take in relation to the matter referred to the Tribunal' (s. 103(4), Pensions Act 2004).

It is yet to be seen how the tribunal will consider what is appropriate, but, based on the proposed procedure for the tribunal's review (involving the scrutiny of the regulator's reasons for its actions and the evaluation of evidence discussed further below), its function will be to make a fresh appraisal of matters referred to it. It is likely that it will take a judicial approach to references, as do many other statutory tribunals: '[tribunals] find facts and then apply legal rules to them impartially, without regard to executive policy'. ${ }^{2}$

It is clear that the tribunal will be equipped with extensive powers to react to grievances raised by parties. Once it 
has carried out its consideration of a reference, the tribunal will have discretion to confirm the regulator's decision or direct the regulator to vary or revoke its determination or substitute a different determination (s. 103(6)). In addition, the tribunal may, on determining a reference, make recommendations as to the relevant procedure to be followed by the regulator (or the panel) in the future (s. 103(8)), so its decisions may have a wider impact beyond the reference in hand.

\section{The tribunal's procedure}

Schedule 4 to the Act provides that the Lord Chancellor will make procedural rules for the tribunal. On 7th December, 2004, the Department for Constitutional Affairs issued a draft set of pensions regulator tribunal rules, 2005 for a consultation ending on 18th February, 2005. These set out what is essentially quite a formal adversarial procedure, allowing for written submissions, the exchange of evidence and, in certain cases, a full hearing. The following main steps are proposed:

- The applicant's reference will need to be made in writing by way of a 'reference notice' setting out certain information such as the details of the scheme concerned and the issues which the applicant wishes the tribunal to consider. (There are detailed requirements for effective notice.)

- The regulator shall file a written statement of case in support of its decisions which are the subject of the dispute and send a copy to the applicant. This will include the reasons for its determination and all the matters and facts on which the regulator relies in support of its action (including a list of relevant evidential material which either supports or undermines its case).

- The applicant then shall file a written reply setting out the grounds on which it relies in its reference and identifying which of the matters contained in the statement of case are in dispute and why. It will also provide its own list of disclosure documents, but, significantly and in favour of the applicant, only including the material which supports its case.

- The regulator is allowed to give further disclosure once it has seen the applicant's reply.

- Throughout these initial stages, and afterwards, the tribunal may give directions as to the practice and procedure to be followed.

- It seems that, in most cases, there will be an oral hearing held by the tribunal to review the regulator's decision. The tribunal may only determine a reference or a particular issue without an oral hearing if:

- the parties agree this in writing;

- the issue concerns an application for directions;

- the regulator states that it does not oppose the reference or the regulator does not file a statement of case in time; or

- the applicant does not file a reply in time (although in this case, the applicant would be given the opportunity to make representations before the tribunal made any determination).

- The tribunal may limit an oral hearing to a preliminary issue of fact or law and may treat it as the hearing of the entire reference if the determination of the question substantially disposes of the reference.

- The hearing will be conducted by the tribunal in the manner it considers most suitable, subject to the 
provisions of the Act and the tribunal rules. Its powers include the ability to summon witnesses to attend a hearing to give evidence and to order the production or inspection of documents.

- All hearings shall be in public unless the tribunal is persuaded that all or part of the hearing should be held in private where the circumstances permit and where this would not prejudice the interests of justice.

- In some ways the procedure is quite flexible. Evidence may be admitted by the tribunal whether or not it would be admissible in a court of law. It may consider evidence whether or not it was available to the regulator at the material time. The parties may be represented, but the representative does not have to be a legally qualified person.

- Echoing the approach of the Civil Procedure Rules of court and their overriding objectives, the tribunal will be concerned actively to manage the conduct of the reference. Clause 10 of the draft rules states that the tribunal will seek to 'ensure the just, expeditious and economical determination of the reference'.

- The tribunal will be able to order that any statement can be struck out at any stage of the proceedings on the ground that it is scandalous, frivolous or vexatious. Further, it is proposed that it may also penalise poor conduct of the parties by ordering that any reference itself can be struck out for want of prosecution (draft clause 32) or for failure to comply with directions (possibly with a costs order against the offending party) - draft clause 33. Such powers may be directed at the regulator as much as against the applicant.

- As to the power to make a costs order, this is established in para. 13 of
Schedule 4 to the Act, and the procedure will be provided in the rules (draft clause 26). A costs order may be made where any party has acted vexatiously, frivolously or unreasonably or where the regulator's decision was found to be unreasonable, but not otherwise.

- The Act also provides that an order of the tribunal may be enforced as if it were an order of a county court or, in Scotland, as if it were an order of the Court of Session (s. 103(9)).

\section{The tribunal reviewing itself}

It appears that the tribunal will be able to review its own decisions to a limited extent. The draft rules provide that where a decision was wrongly made as a result of an error on the part of the tribunal staff or if new evidence becomes available since the conclusion of the hearing, the tribunal can review and confirm or set aside the decision (draft clause 27). If it sets aside the decision, then it can either substitute a decision or order a re-hearing before either the same or a differently constituted tribunal.

Although it is not entirely clear from the draft rules or the Act what sort of error is contemplated here, it is likely to relate to administrative errors rather than substantive issues. This may be something that is clarified through the consultation process on the draft rules.

\section{Appeals from the tribunal}

The final opportunity to challenge the regulator's actions, under the statutory framework at least, is the provision for appeals from the tribunal on a point of law (s. 104).

The provision for appeal from the tribunal is more far-reaching than that available in respect of Opra's decisions. If a person is dissatisfied with a decision by 
Opra's review committee or aggrieved by that body's refusal to review its decision, he can appeal to the High Court (only on a point of law) and that court's decision is final (s. 97, Pensions Act 1995).

In contrast, a party may appeal from the tribunal to the Court of Appeal on a point of law either with leave of the tribunal or of the Court of Appeal if the tribunal refuses leave. If the Court considers that the decision of the tribunal was wrong in law, it may remit the matter to the tribunal for a rehearing and determination or itself make a determination. If still dissatisfied, a party can appeal further from a decision of the appeal court, but only with the leave of the Court of Appeal (or Court of Session) or, where applicable, of the House of Lords.

\section{Conclusions}

The new regulator will have significant powers that can be exercised against a very large group of individuals and businesses concerned with pension schemes. To counterbalance this, the legislature has provided extensive rights for those concerned. The regulator's decision-making process is structured and allows for those concerned to make representations before decisions are made. Many decisions, particularly those relating to the exercise of the most important powers (such as the moral hazard powers), are taken by a fully independent panel. Determinations of the regulator can be referred as of right to an independent statutory tribunal for review. In addition there are full rights of appeal to the highest appeal courts from the tribunal on points of law.

It is likely that many decisions taken by the regulator will be challenged by referring them to the tribunal for review. The fact that there is only very limited scope for the tribunal to make costs orders in relation to proceedings before it, will encourage references, as surely was the intention. References may also be encouraged by the fact that the procedure in some respects favours the applicant over the regulator (eg the absence of a requirement for the applicant to disclose unfavourable documents) and, less legitimately, by the fact that a reference to the tribunal will result in many cases in what will in effect be a stay on the enforcement of the regulator's decision. Some may be discouraged from referring decisions to the tribunal (particularly when the means of the applicant are limited or the decision does not have substantial financial consequences) because the tribunal's relatively full procedure will involve a certain amount of expense. The tribunal does have the power, however, to adapt its procedures to suit the reference before it and if these powers are sensibly exercised this should not in practice prove any real disincentive.

The effectiveness in practice of the checks on the regulator's exercise of its powers will depend to a large degree on the approach taken by the tribunal and whether it can demonstrate itself to be independent of the regulator. The tribunal's structural independence from the regulator, its proposed procedures and the legal elements of its composition will assist it in establishing itself as a creditable forum for challenges against the regulator. Its actions will certainly come under considerable scrutiny from commentators and almost certainly the courts.

The number of references to the tribunal will inevitably be higher at the start, as the approach of the regulator is put to the test. We can also expect a number of appeals on points of law from the tribunal to the Court of Appeal at 
the outset, while the exact scope of the regulator's powers and circumstances in which they may be exercised are determined by the courts.

The legislature was clearly mindful of the extensive powers that the regulator will have when considering the framework in the Act for challenging the exercise of those powers and has tried to ensure that the procedures will meet the requirements of the Human Rights Act 1998 and the requirements of administrative law, to which they will be subject. ${ }^{3}$ The second paper considers what scope there may be for using administrative law to challenge the decisions of the regulator and the tribunal using judicial review.

\section{References and notes}

1 Occupational pension schemes or personal pension schemes (where direct payment arrangements exist in respect of one or more members of the scheme who are employees) or stakeholder pension schemes (s. 5 of the Act).

2 Wade, H. W. R. and Forsyth, C. F. 'Administrative Law', 9th edn, Oxford University Press, Oxford, p. 909.

3 Explanatory notes to the Pensions Bill: 'Decisions of the Regulator will often involve the determination of civil rights and obligations within the meaning of ECHR, Article 6. The procedures set out in the Bill will ensure that disputes relating to such decisions will be determined by an Article 6 compliant process' (May 2004). 